\title{
Radioiodine therapy in benign thyroid disease
}

\section{J Nicholson, F Catling, M Moorthy, A Garg, P Hyatt, C Nethaji}

North Middlesex University Hospital NHS Trust

\section{Background}

Radioiodine is a safe and effective treatment for benign thyroid disease. It aims to treat hyperthyroidism and achieve a euthyroid state. Radioiodine

is indicated in cases of hyperthyroidism caused by Graves' disease or toxic goitre (solitary toxic adenomas or multinodular goitre).In practice there has been concerns about long term safety, worsening of eye disease and weight gain with this treatment.

\section{Methods}

A retrospective review of patients treated with Radioiodine at North Middlesex Hospital between January 2012 and December 2014. All patients were treated with $555 \mathrm{MBq}$ as a fixed dose.

\section{Results}

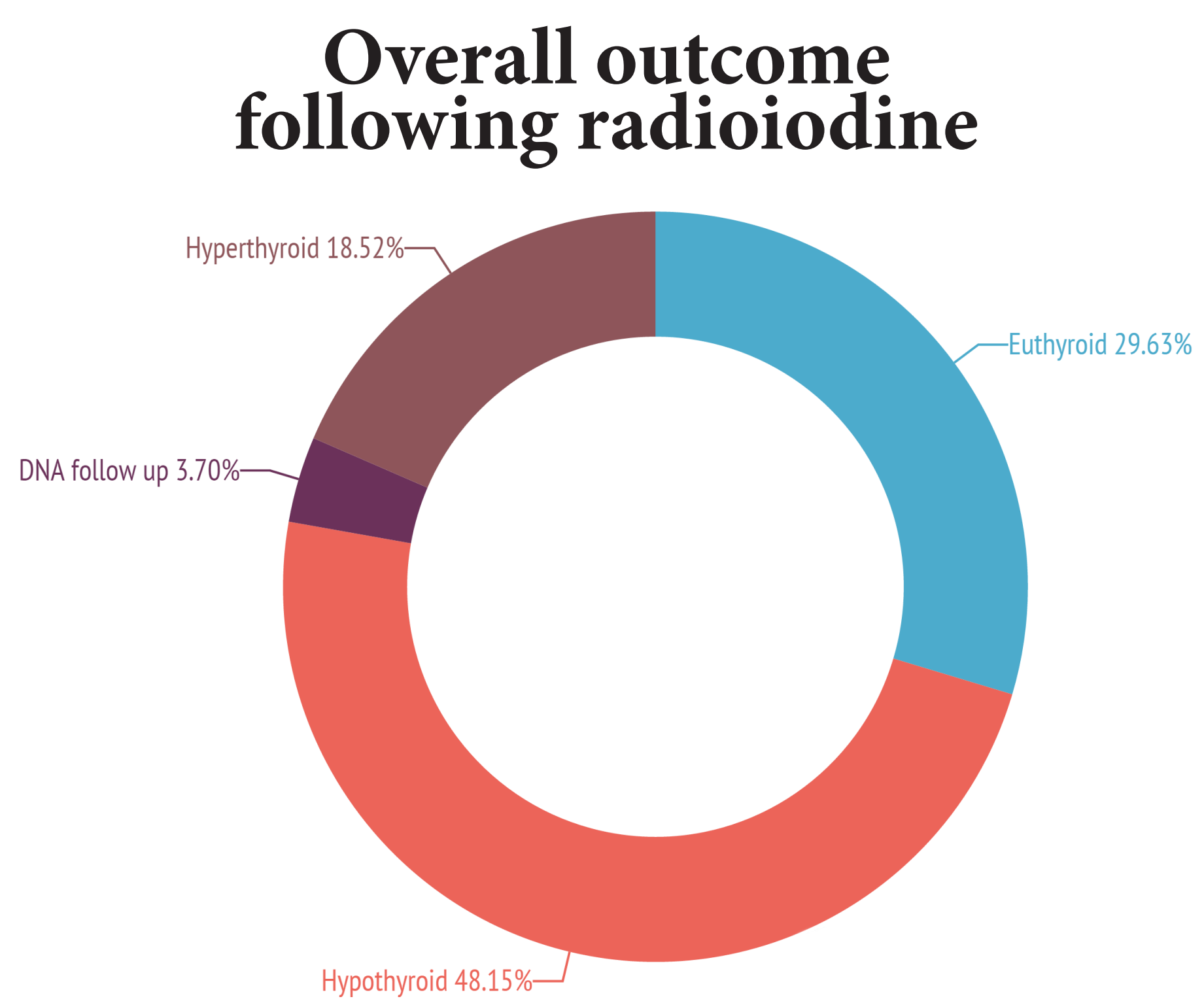

- Total number of patient 27. Average age was 49 years (21-88). 23 patients $(88 \%)$ were on antithyroid therapy prior to radioiodine treatment.

- 21 patients (78\%) had their thyroid function checked at approximately 6 weeks and only 11 patients $(40 \%)$ had it rechecked at 12 weeks. 23 patients (85\%) had ongoing thyroid function monitoring at 1 year.

- Overall outcome 13 patients (48\%) became hypothyroid requiring levothyroxine, 8 patients (29\%) became euthyroid, 5patients (18\%) remained hyperthyroid and 1 did not attend follow up.

- Average time to commence levothyroxine was 4.5 months.

- 16 patients (59\%) gained weight with an average weight gain of $4.9 \mathrm{KG}$ over 12 months.

\section{Discussion}

There were no other complications of Radioiodine treatment recorded. We conclude that with appropriate patient selection and monitoring, Radioiodine treatment for benign thyroid disease is a safe and effective treatment option.

\section{Citations}

1. Royal College of Physicians. Radioiodine in the management of benign thyroid disease, 2007. https://www.rcplondon.ac.uk/sites/default/files/ documents/radioiodine-management-benignthyroid-disease.pdf (accessed 15/10/2015).

\section{Further Information}

For more information, please scan the QR code or email Jill Nicholson at jillynicholson@gmail.com 